\title{
Model GARCH dengan Pendekatan Conditional Maximum Likelihood untuk Prediksi Harga Saham
}

\author{
Cipta Rahmadayanti ${ }^{\# 1}$, Hasbi Rabbani ${ }^{* 2}$, Aniq Atiqi Rohmawati ${ }^{\# 3}$ \\ \# Departement of Computational Science, School of Computing \\ Telkom University \\ 1 ciptard@ student.telkomuniversity.ac.id \\ ${ }^{1}$ hasbirabb@student.telkomuniversity.ac.id \\ 3 aniqatiqi@telkomuniversity.ac.id
}

\begin{abstract}
Stock price predictions are useful for investors to know how the investment flow works in the future. To obtain a big profit investors can conduct analysis in predicting stock prices. However, investors can not predict stock prices easily because of fluctuations in stock prices change quickly every time. Basically predictions can be done using several methods, but by using time series model is expected to obtain a better and optimal prediction because the characteristics of the stock data is time series data that moves over time continuously. Therefore, in this paper, authors used GARCH time series model with Conditional Maximum Likelihood approach to predict the stock price. The important parameter values in $\operatorname{GARCH}(1,1)$ model are $\alpha_{0}, \alpha_{1}, \beta_{1}$, which can be used to obtain predicted value. Based on the analysis, the GARCH $(1,1)$ model with Conditional Maximum Likelihood approach is a good model to predict the return and stock price of NASDAQ with 0,000274 RMSE result. Then, based on GARCH $(1,1)$ investors can make a strategy to invest their money in NASDAQ stock index in order to obtain more profit.
\end{abstract}

Keywords: Stock Price, GARCH Model, Conditional Maximum Likelihood.

\begin{abstract}
Abstrak
Prediksi harga saham berguna untuk para investor untuk mengetahui bagaimana alur investasi bekerja pada masa yang akan datang. Untuk mendapatkan keuntungan yang besar investor dapat melakukan analisis dalam memprediksi harga saham. Namun investor tidak dapat memprediksi harga saham dengan mudah dikarenakan fluktuasi harga saham berubah dengan cepat setiap waktunya. Pada dasarnya prediksi dapat dilakukan dengan menggunakan beberapa metode, namun dengan menggunakan model time series diharapkan menghasilkan prediksi yang baik dan optimal karena karakteristik dari data saham merupakan data time series yang bergerak kontinu terhadap waktu. Pada penelitian ini digunakan model time series GARCH dengan pendekatan Conditional Maximum Likelihood untuk memprediksi harga saham. Nilai parameter yang penting dalam model $\operatorname{GARCH}(1,1)$ adalah $\alpha_{0}, \alpha_{1}, \beta_{1}$. Hasil penaksiran parameter dengan Conditional Maximum Likelihood digunakan untuk memperoleh hasil prediksi. Berdasarkan hasil analisis, model $\operatorname{GARCH}(1,1)$ dengan pendekatan Conditional Maximum Likelihood adalah model yang baik untuk memprediksi harga saham NASDAQ dengan RMSE sebesar 0,000274. Berdasarkan hasil prediksi model $\operatorname{GARCH}(1,1)$, maka para investor dapat membuat strategi pada indeks saham NASDAQ agar dapat menghasilkan keuntungan.
\end{abstract}

Kata Kunci: Harga Saham, Model GARCH, Conditional Maximum Likelihood. 
Cipta Rahmadayanti et.al.

\section{INTRODUCTION}

$\mathbf{P}$ ADA zaman ini pasar modal dalam perekonomian dunia makin berkembang. Investasi, saat ini menjadi salah satu kegiatan yang banyak diminati berbagai kalangan masyarakat, dengan mengakumulasikan suatu bentuk aktiva dengan suatu harapan mendapatkan keuntungan dimasa depan. Produk investasi bisa berupa tabungan di bank, saham, obligasi(surat utang), emas, properti, serta bisnis sektor real [4]. Jual beli saham merupakan suatu pilihan modal yang sah dan menjanjikan untuk para investor. Investasti berkaitan dengan return, return saham adalah tingkat keuntungan atau kerugian yang didapatkan oleh suatu investor atas investasi yang dilakukan pada saham tertentu.

Terdapat beberapa penelitian untuk memprediksi harga saham, pada jurnal yang ditulis oleh Enke, et al [5] dilakukan prediksi return saham menggunakan data mining dan neural networks, serta Oztekin, et al pada jurnal [6] mengkaji tentang prediksi return saham harian pada pasar berkembang dengan pendekatan analitik. Pada penelitian tersebut dengan melakukan uji statistik $t$ untuk model neural network dapat dikatakan bahwa selain model GRNN dan PNN, secara signifikan mengungguli prediksi regresi linier konvensional pada tingkat kepercayaan 95\% [5]. Sedangkan, pada jurnal [7] dilakukan prediksi harga saham berdasarkan data historis menggunakan model regresi yang dibangun dengan algoritma genetika, menghasilkan nilai MSE terkecil yaitu 47,5023 yang didapatkan oleh harga prediksi hasil perhitungan algortima genetika, hal itu membuktikan bahwa koefisien terbaik hasil perhitngan algoritma genetika dapat digunakan untuk prediksi harga saham.

Pada penelitian yang dilakukan kali ini terkait pemodelan time series untuk memprediksi harga saham dengan efek ARCH. Pemodelan time series dilakukan untuk meramalkan nilai-nilai masa depan yang didasarkan pada nilai-nilai masa lampau. Ide untuk memprediksi harga saham menggunakan model time series adalah karna data saham merupakan data time series yang bergerak kontinu terhadap waktu. Pada dasarnya, model time series dibagi menjadi dua, dengan melihat perilaku atau volatilitas data, model Homoskedastis dan Heteroskedastis. Model Homoskedastis diantaranya Autoregressive (AR), Moving Average(MA), ARMA. Model Heteroskedastis berupa ARI, IMA, ARIMA. Pada penelitian ini digunakan model time series dengan mempertimbangkan hasil uji efek ARCH yang dilakukan. Model yang digunakan pada penelitian ini adalah model Generealized Autoregressive Conditional Heteroskedasticity (HARCH) orde $(1,1)$, yang dimplementasikan pada data return saham NASDAQ.

Model GARCH dapat digunakan untuk peramalan atau estimasi, pada jurnal [8] dilakukan estimasi VaR (Value-at-Risk) dengan menggunakan model GARCH-M. Misalkan $Y_{t}$ merupakan peubah acak return saham pada saat $t$, dengan diketahui $Y_{1}, Y_{2}, \ldots, Y_{t}$ merupakan peubah acak yang terobservasi. Estimasi parameter model time series secara khusus menggunakan pendekatan Conditional Maximum Likelihood pada perhitungan mean dan variansi,

$$
\begin{gathered}
E\left(Y_{t} \mid Y_{1}, Y_{2}, \ldots, Y_{t-1}\right) \\
\operatorname{Var}\left(Y_{t} \mid Y_{1}, Y_{2}, \ldots, Y_{t-1}\right)
\end{gathered}
$$

Pada bagian Uji Efek ARCH pada jurnal ini, dibahas apakah suatu data saham mengandung kondisi heteroskedastis untuk mengidentifikasi model model time series. Pada bagian III jurnal ini, dibahas model GARCH(1,1) berdasarkan uji efek ARCH. Pada bagian IV jurnal ini, dibahas penaksiran parameter dengan menggunakan ekspektasi dan variansi bersyarat. Pada bagian V jurnal ini, dibahas mengenai implementasi model $\operatorname{GARCH}(1,1)$ berdasarkan penaksir parameter yang didapat.

\section{UJI EFEK ARCH}

Uji efek ARCH adalah salah satu metode yang digunakan untuk mengetahui kondisi heteroskedastisitas pada data. Kondisi heteroskedastisitas adalah kondisi dimana pergarakan data yang tidak homogen. Uji efek ARCH sendiri dilakukan untuk mengetahui apakah data dapat dimodelkan dengan time series heteroskedastis atau tidak. Brooks [3] mendefinisikan uji efek ACRH dengan langkah-langkah sebagai berikut:

- Definisikan model deret waktu.

$$
L_{t}=y_{t}-\bar{y}_{t}
$$


- Tentukan bentuk regresi linear mengikuti model ARCH (m).

$$
L_{t}^{2}=\alpha_{0}+\alpha_{1} L_{t-1}^{2}+\alpha_{2} L_{t-2}^{2}+\ldots+\alpha_{m} L_{t-m}^{2}+\epsilon_{t}
$$

- Tentukan hipotesis nol dan hipotesis tandingannya.

$$
\begin{gathered}
H_{0}: \alpha_{0}=\alpha_{1}=\alpha_{2}=\ldots=\alpha_{m}=0 \\
H_{1}: \alpha_{i} \neq 0, i=1,2, . ., m
\end{gathered}
$$

- Menentukan tingkat signifikansi yang akan digunakan.

- Menghitung statistik uji F.

Misalkan $\epsilon_{t} \sim N(0,1)$, definisikan Jumlah Kuadrat Residu (JKR) sebagai berikut:

$$
\begin{gathered}
J K R_{0}=\sum_{t=m+1}^{T}\left(L_{t}^{2}-\bar{L}_{t}\right)^{2} \\
J K R_{1}=\sum_{t=m+1}^{T} \hat{\epsilon}_{t}^{2}
\end{gathered}
$$

dengan $\bar{L}_{t}$ merupakan rataan dari sampel $L_{t}, \hat{\epsilon}_{t}$ adalah penaksir kuadrat terkecil, dan $m$ adalah derajat kebebasan. Distribusi $J K R_{1}$ diperoleh dengan cara yang sama, sehingga $J K R_{1} \sim \chi_{T-(m+1)}^{2}$. Distribusi F dapat diperoleh sebagai berikut :

$$
\frac{\left|J K R_{0}-J K R_{1}\right| / m}{J K R_{1} /(T-m-1)} \sim F_{m, T-m-1},
$$

berdasarkan hasil tersebut, $H_{0}$ ditolak jika $F>\chi_{m}^{2}(\alpha)$, dengan $F>\chi_{m}^{2}(\alpha)$ adalah batas atas dari $(1-\alpha)$.

Pengujian efek ARCH pada saham NASDAQ telah dilakukan dan mendapatkan hasil pada tabel II yang berisi perhitungan menggunakan Statistik Uji F dengan nilai tingkat signifikansi $\alpha=0,01$ dan derajat kebebasan $m=20$. Berdasarkan hasil yang didapat maka dapat dianalisis uji efek ARCH dengan menggunakan perhitungan statistik uji F, pada saham NASDAQ mengandung efek ARCH sehingga dapat diprediksi harga saham dengan menggunakan model time series Heteroskedastis yang pada penelitian ini digunakan model GARCH $(1,1)$.

Tabel I

UJI EFEK ARCH SAHAM NASDAQ

\begin{tabular}{|c|c|}
\hline Indeks Saham & NASDAQ \\
\hline Perhitungan Uji Statistik F & $\mathrm{F}=49,24999662$ \\
\cline { 2 - 2 } & $\chi_{m}^{2}(\alpha)=37,57$ \\
\cline { 2 - 2 } & $* H_{0}$ ditolak jika nilai $\mathrm{F}>\chi_{m}^{2}(\alpha)$ \\
\hline
\end{tabular}

\section{MODEL GARCH( $(1,1)$}

Model Generealized Autoregressive Conditional Heteroscedasticity (GARCH) dikembangkan oleh Bollerslov (1986) dan Taylor (1986) [2]. Pemodelan GARCH merupakan hasil pengembangan dari model Autoregressive Conditional Heteroscedasticity yang dikemukakan oleh Engle (1982). Model GARCH mempunyai orde model $(p, q)$, ditulis sebagai $\operatorname{GARCH}(\mathrm{p}, \mathrm{q})$, dapat dinyatakan sebagai berikut:

$$
\begin{gathered}
y_{t}=\sigma_{t} \cdot \varepsilon_{t} \\
\sigma_{t}^{2}=\alpha_{0}+\alpha_{1} y_{t-1}^{2}+\ldots+\alpha_{p} y_{t-p}^{2}+\beta_{1} \sigma_{t-1}^{2}+\ldots+\beta_{q} \sigma_{t-q}^{2}
\end{gathered}
$$

Berdasarkan bagian Uji efek ARCH, maka ditentukan model time series yang baik untuk memprediksi harga saham yaitu model $\operatorname{GARCH}(1,1)$, model $\operatorname{GARCH}(1,1)$ adalah sebagai berikut:

$$
y_{t}=\sigma_{t} \cdot \varepsilon_{t}
$$


Cipta Rahmadayanti et.al.

$$
\begin{gathered}
\sigma_{t}^{2}=\alpha_{0}+\alpha_{1} y_{t-1}^{2}+\beta_{1} \sigma_{t-1}^{2} \\
\varepsilon_{t} \sim N(0,1)
\end{gathered}
$$

dengan $\sigma_{t}^{2}$ adalah variansi bersyarat yang dihitung berdasarkan informasi variansi periode sebelumnya.

\section{Conditional Maximum Likelihood Estimation (CMLE)}

Pada bagian sebelumnya telah dilakukan pengujian efek $\mathrm{ARCH}$, serta didapatkan model yang baik dengan mempertimbangkan hasil uji efek $\mathrm{ARCH}$, maka selanjutnya dilakukan estimasi parameter untuk mencari nilai parameter yang baik untuk model $\operatorname{GARCH}(1,1)$. Untuk melakukan estimasi parameter model $\operatorname{GARCH}(1,1)$ perlu memperhitungkan ekspektasi bersyarat dan variansi bersyarat terhadap $Y_{t-1}$,

- Ekspektasi Bersyarat

$$
\begin{aligned}
E\left(Y_{t} \mid Y_{t-1}, \sigma_{t-1}\right) & =E\left(\sigma_{t} \cdot \varepsilon_{t} \mid y_{t-1}, \sigma_{t-1}\right) \\
& =E\left(\sqrt{\alpha_{0}+\alpha_{1} y_{t-1}^{2}+\beta_{1} \sigma_{t-1}^{2}} \mid y_{t-1}, \sigma_{t-1}\right) \cdot E\left(\varepsilon_{t} \mid y_{t-1}, \sigma_{t-1}\right) \\
& =0
\end{aligned}
$$

- Variansi Bersyarat

$$
\begin{aligned}
\operatorname{Var}\left(Y_{t} \mid Y_{t-1}, \sigma_{t-1}\right) & =E\left(y_{t}^{2} \mid y_{t-1}, \sigma_{t-1}\right)-\left[E\left(y_{t} \mid y_{t-1}, \sigma_{t-1}\right)\right]^{2} \\
& =E\left(\sigma_{t}^{2} \mid y_{t-1}, \sigma_{t-1}\right) \cdot E\left(\varepsilon_{t}^{2} \mid y_{t-1}, \sigma_{t-1}\right)-\left[E\left(\sigma_{t} \mid y_{t-1}, \sigma_{t-1}\right)\right]^{2} \cdot\left[E\left(\varepsilon_{t} \mid y_{t-1}, \sigma_{t-1}\right)\right]^{2} \\
& =\sigma_{t}^{2}
\end{aligned}
$$

Ekspektasi dan variansi bersyarat telah didapatkan, maka untuk Conditional Maximum Likelihood Estimation (CMLE) dapat dihitung berdasarkan fungsi kepadatan peluang distribusi normal dengan ekspektasi dan variansi bersyarat, masing-masing adalah ekspektasi bersyarat dan variansi bersyarat,

$$
\begin{gathered}
f_{Y_{t}}\left(Y_{t} \mid Y_{t-1}, \sigma_{t-1}\right)=\frac{1}{\sqrt{2 \pi \cdot \sigma_{t}^{2}}} \exp \left(-\frac{1}{2} \cdot \frac{\left(y_{t}-\mu\right)^{2}}{\sigma_{t}^{2}}\right) \\
=\frac{1}{\sqrt{2 \pi \cdot\left(\alpha_{0}+\alpha_{1} y_{t-1}^{2}+\beta_{1} \sigma_{t-1}^{2}\right)}} \exp \left(-\frac{1}{2} \cdot \frac{\left(y_{t}\right)^{2}}{\left(\alpha_{0}+\alpha_{1} y_{t-1}^{2}+\beta_{1} \sigma_{t-1}^{2}\right)}\right)
\end{gathered}
$$

untuk memperoleh nilai penaksir parameter $\alpha_{0}, \alpha_{1}$, dan $\beta_{1}$ dengan menggunakan fungsi likelihood adalah

$$
\begin{gathered}
L\left(\alpha_{0}, \alpha_{1}, \beta_{1} \mid\left(Y_{t} \mid Y_{t-1}, \sigma_{t-1}\right)=\prod_{t=2}^{n} \frac{1}{\sqrt{2 \pi \cdot\left(\alpha_{0}+\alpha_{1} y_{t-1}^{2}+\beta_{1} \sigma_{t-1}^{2}\right)}} \exp \left(-\frac{1}{2} \cdot \frac{\left(y_{t}\right)^{2}}{\left(\alpha_{0}+\alpha_{1} y_{t-1}^{2}+\beta_{1} \sigma_{t-1}^{2}\right)}\right)\right. \\
l(\delta)=\log \left(L \left(\alpha_{0}, \alpha_{1}, \beta_{1} \mid\left(Y_{t} \mid Y_{t-1}, \sigma_{t-1}\right)\right.\right. \\
=-\frac{1}{2} \sum_{t=2}^{n}\left(\log (2 \pi)+\log \left(\alpha_{0}+\alpha_{1} y_{t-1}^{2}+\beta_{1} \sigma_{t-1}^{2}\right)+\frac{y_{t}^{2}}{\left(\alpha_{0}+\alpha_{1} y_{t-1}^{2}+\beta_{1} \sigma_{t-1}^{2}\right)}\right)
\end{gathered}
$$

Selanjutnya, untuk memperoleh nilai parameter $\alpha_{0}$, fungsi log likelihood (6) diturunkan terhadap $\alpha_{0}$, turunan pertama fungsi log likelihood terhadap $\alpha_{0}$ yaitu:

$$
\begin{gathered}
\frac{\partial l}{\partial \alpha_{0}}=-\frac{1}{2} \sum_{t=2}^{n}\left(\frac{1}{\left(\alpha_{0}+\alpha_{1} y_{t-1}^{2}+\beta_{1} \sigma_{t-1}^{2}\right)}-\frac{y_{t}^{2}}{\left(\alpha_{0}+\alpha_{1} y_{t-1}^{2}+\beta_{1} \sigma_{t-1}^{2}\right)^{2}}\right) \\
\frac{\partial l}{\partial \alpha_{0}}=-\frac{1}{2} \sum_{t=2}^{n}\left(\frac{\left(\alpha_{0}+\alpha_{1} y_{t-1}^{2}+\beta_{1} \sigma_{t-1}^{2}\right)-y_{t}^{2}}{\left(\alpha_{0}+\alpha_{1} y_{t-1}^{2}+\beta_{1} \sigma_{t-1}^{2}\right)^{2}}\right)=0
\end{gathered}
$$


Selanjutnya, untuk memperoleh nilai parameter $\alpha_{1}$, fungsi log likelihood (6) diturunkan terhadap $\alpha_{1}$, turunan terhadap $\alpha_{1}$ yaitu:

$$
\begin{gathered}
\frac{\partial l}{\partial \alpha_{1}}=-\frac{1}{2} \sum_{t=2}^{n} y_{t-1}^{2}\left(\frac{1}{\left(\alpha_{0}+\alpha_{1} y_{t-1}^{2}+\beta_{1} \sigma_{t-1}^{2}\right)}-\frac{y_{t}^{2}}{\left(\alpha_{0}+\alpha_{1} y_{t-1}^{2}+\beta_{1} \sigma_{t-1}^{2}\right)^{2}}\right) \\
\frac{\partial l}{\partial \alpha_{1}}=-\frac{1}{2} \sum_{t=2}^{n}\left(\frac{\left(\alpha_{0} y_{t-1}^{2}+\alpha_{1} y_{t-1}^{4}+\beta_{1} y_{t-1}^{2} \sigma_{t-1}^{2}\right)-y_{t}^{2}\left(y_{t-1}^{2}\right)}{\left(\alpha_{0}+\alpha_{1} y_{t-1}^{2}+\beta_{1} \sigma_{t-1}^{2}\right)^{2}}\right)=0
\end{gathered}
$$

Selanjutnya, untuk memperoleh nilai parameter $\beta_{1}$, fungsi log likelihood (6) diturunkan terhadap $\beta_{1}$, turunan terhadap $\beta_{1}$ yaitu:

$$
\begin{gathered}
\frac{\partial l}{\partial \beta_{1}}=-\frac{1}{2} \sum_{t=2}^{n} \sigma_{t-1}^{2}\left(\frac{1}{\left(\alpha_{0}+\alpha_{1} y_{t-1}^{2}+\beta_{1} \sigma_{t-1}^{2}\right)}-\frac{y_{t}^{2}}{\left(\alpha_{0}+\alpha_{1} y_{t-1}^{2}+\beta_{1} \sigma_{t-1}^{2}\right)^{2}}\right) \\
\frac{\partial l}{\partial \alpha_{1}}=-\frac{1}{2} \sum_{t=2}^{n}\left(\frac{\left(\alpha_{0} \sigma_{t-1}^{2}+\alpha_{1} y_{t-1}^{2} \sigma_{t-1}^{2}+\beta_{1} \sigma_{t-1}^{4}\right)-y_{t}^{2}\left(\sigma_{t-1}^{2}\right)}{\left(\alpha_{0}+\alpha_{1} y_{t-1}^{2}+\beta_{1} \sigma_{t-1}^{2}\right)^{2}}\right)=0
\end{gathered}
$$

Untuk estimasi parameter model GARCH $(1,1)$ melibatkan perhitungan volatilitas, perhitungan volatilitas menggunakan data historis dari return saham pada interval waktu tertentu [1], berikut adalah volatilitas awal yang digunakan:

$$
\sigma_{t}^{2}=\frac{1}{(n-1)} \cdot \sum_{t=1}^{n} R_{t}^{2}
$$

\section{Simulasi GARCH(1,1) Berdasarkan CMLE}

Data yang digunakan pada penelitian kali ini yaitu harga indeks saham NASDAQ yang merupakan bursa saham internasional. NASDAQ adalah bursa saham terbesar di Amerika Serikat dengan lebih dari setengah jumlah perusahaan yang diperdagangkan di AS dicatat di bursa ini.
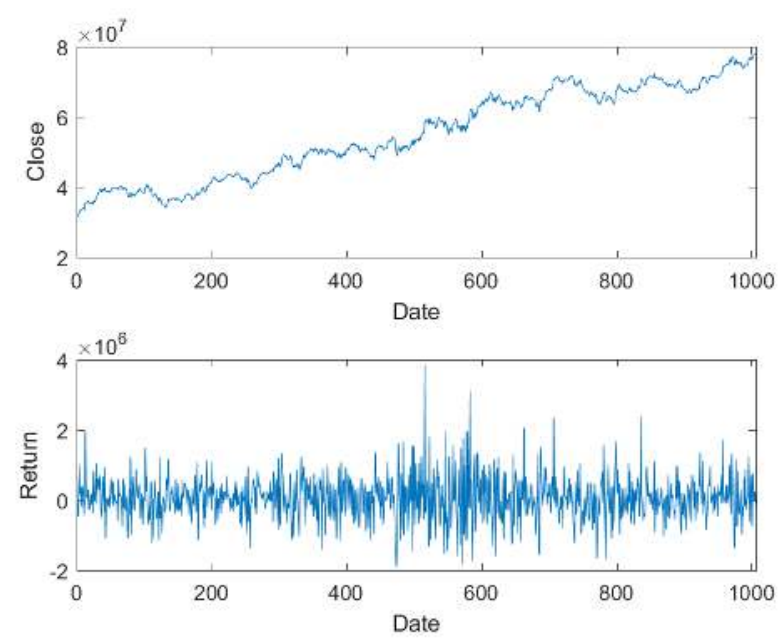

Gambar 1. Grafik Harga Indeks Saham \& Return Saham NASDAQ

Pertama, data saham yang telah didapat dicari return saham nya, pada Gambar 1 dapat dilihat yaitu grafik harga saham NASDAQ dan grafik return yang didapatkan. Pada Gambar 1 terlihat volatilitas 
Cipta Rahmadayanti et.al.

(pergerakan) return saham dibeberapa rentang nilai return memiliki kondisi ekstrim tetapi mayoritas nilai return adalah stasioner. Selanjutnya, dilakukan pengujian efek ARCH yang sudah dilakukan pada bagian Uji Efek ARCH. Berdasarkan hasil pengujian efek ARCH yang telah dilakukan, maka dapat disimpulkan bahwa model time series yang baik digunakan untuk data harga indeks saham NASDAQ adalah model GARCH(1,1). Berdasarkan model GARCH(1,1) yang sudah dibahas pada bagian sebelumnya, maka dapat diperoleh formula model GARCH(1,1),

$$
\begin{gathered}
Y_{t}=\sigma_{t} \cdot \varepsilon_{t} \\
\sigma_{t}^{2}=\alpha_{0}+\alpha_{1} y_{t-1}^{2}+\beta_{1} \sigma_{t-1}^{2}
\end{gathered}
$$

Model yang baik untuk data saham sudah didapatkan dari pengujian efek ARCH, maka selanjutnya dilakukan estimasi parameter untuk mencari nilai parameter yang baik untuk model GARCH(1,1) yang sudah dilakukan pada bagian Conditional Maximum Likelihood Estimation. Jumlah data return yang digunakan pada penelitian kali ini sebanyak 1007 data. Penaksir parameter telah didapatkan pada persamaan $(7,8$, 9), tidak dapat dilakukan penyelesaian secara sederhana, oleh karena itu digunakan fungsi fminsearch sehingga didapat nilai estimasi parameter yang dibutuhkan model GARCH(1,1). Untuk estimasi parameter menggunakan banyak data return adalah sebanyak 1007 data, tidak ada pembagian data estimasi dan data uji. Nilai parameter yang didapat untuk memaksimumkan fungsi likelihood pada persamaan (6) adalah:

$$
\begin{aligned}
& \hat{\alpha}_{0}=0,00011 \\
& \hat{\alpha}_{1}=0,16677 \\
& \hat{\beta}_{1}=0,03179
\end{aligned}
$$

Selanjutnya, nilai parameter dimasukkan kedalam model $\operatorname{GARCH}(1,1)$ pada persamaan (11) untuk mengetahui hasil prediksi. Untuk prediksi dibutuhkan nilai $\varepsilon_{t}$ yang sudah digenerate menggunakan distribusi normal. Berikut adalah grafik prediksi yang didapat dengan model $\operatorname{GARCH}(1,1)$ :

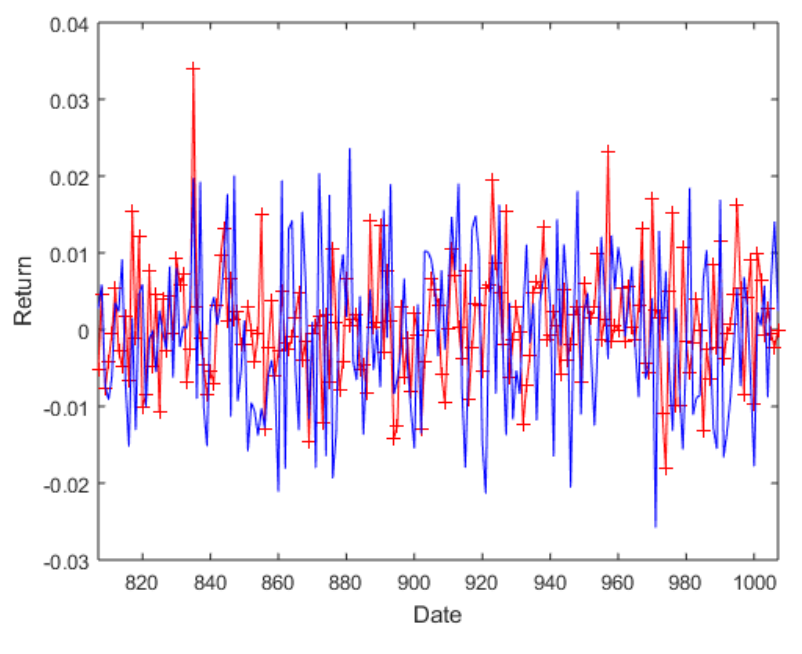

Gambar 2. Grafik Hasil Prediksi Return dengan Model GARCH(1,1)

Pada Gambar 2 terlihat grafik return saham data real dan return saham hasil prediksi dengan mengambil sampel data sebanyak 200 data, terdapat kemiripan tren dari grafik yang dihasilkan. Bersesuaian dengan harga saham dan return NASDAQ real pada Gambar 1, pada Gambar 3 dapat dilihat yaitu grafik hasil prediksi harga saham dan return NASDAQ dengan $\operatorname{GARCH}(1,1)$ dibandingkan dengan data real pada 1000 observasi, terlihat bahwa model GARCH(1,1) berbasis CMLE dapat mengakomodir tren data real dan menghasilkan nilai RMSE sebesar 0,000274, grafik yang berwarna biru adalah data hasil prediksi dengan $\operatorname{GARCH}(1,1)$ berbasis CMLE dan grafik berwarna merah adalah data real. 

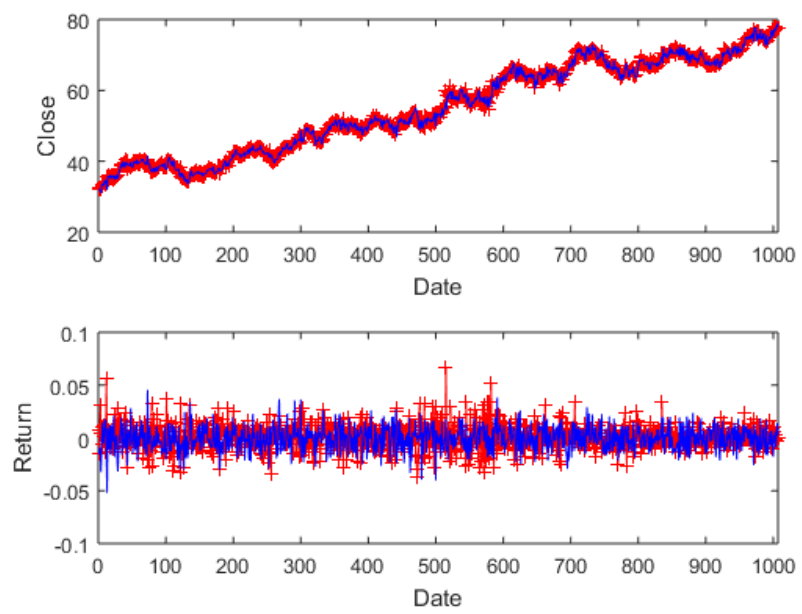

Gambar 3. Grafik Hasil Prediksi Harga Indeks Saham \& Return Saham NASDAQ

\section{KeSIMPULAN}

Berdasarkan model GARCH(1,1) dengan mempertimbangkan Conditional Maximum Likelihood Estimation (CMLE) untuk estimasi parameter model, maka model GARCH(1,1) menghasilkan nilai prediksi dengan RMSE yang kecil yaitu sebesar 0,000274 pada return indeks harga saham NASDAQ. Oleh karena itu, model time series $\operatorname{GARCH}(1,1)$ berbasis CMLE dapat digunakan untuk memprediksi return saham dengan baik.

\section{PUSTAKA}

[1] Vanessa Aurora. Volatilitas Asimetrik dan Model Volatilitas Stokastik. PhD thesis, Tesis. Institut Teknologi Bandung, Bandung, 2013.

[2] Tim Bollerslev. Generalized autoregressive conditional heteroskedasticity. Journal of econometrics, 31(3):307-327, 1986.

[3] Chris Brooks. Introductory econometrics for finance. Cambridge university press, 2014.

[4] Marek Capinski and Tomasz Zastawniak. Mathematics for finance. An Introduction, pages 118-124, 2003.

[5] David Enke and Suraphan Thawornwong. The use of data mining and neural networks for forecasting stock market returns. Expert Systems with applications, 29(4):927-940, 2005.

[6] Asil Oztekin, Recep Kizilaslan, Steven Freund, and Ali Iseri. A data analytic approach to forecasting daily stock returns in an emerging market. European Journal of Operational Research, 253(3):697-710, 2016.

[7] Asyrofa Rahmi, Wayan Firdaus Mahmudy, and Budi Darma Setiawan. Prediksi harga saham berdasarkan data historis menggunakan model regresi yang dibangun dengan algoritma genetika'. DORO: Repository Jurnal Mahasiswa PTIIK Universitas Brawijaya, 5(12), 2015.

[8] Evi Sufianti. Model GARCH-M untuk estimasi Value at Risk (VaR) data harga saham. PhD thesis, Universitas Islam Negeri Maulana Malik Ibrahim, 2011. 
